Manuscript Number: EID-21-0406

Running Title: Rickettsia japonica in ticks from Thailand

Keywords: Rickettsia japonica, Spotted fever group, ticks, Thailand

\title{
Rickettsia japonica in ticks infesting a wild mammal in Thailand
}

\section{Authors:}

Supanee Hirunkanokpun, Arunee Ahantarig, Visut Baimai, Pairot Pramual, Wachareeporn

Trinachartvanit

\section{Affiliations:}

Ramkhamhaeng University, Bangkok, Thailand (S. Hirunkanokpun)

Mahidol University, Phayathai, Bangkok, Thailand (A. Ahantarig, V. Baimai, W. Trinachartvanit)

Mahasarakham University, Maha Sarakham, Thailand (P. Pramual)

\author{
Abstract-50 words \\ We report the first case of Rickettsia japonica in Haemaphysalis hystricis ticks collected \\ from a Burmese ferret-badger in Loei province, northeastern Thailand. Phylogenetic analyses of \\ ompA and $о m p \mathrm{~B}$ genes clearly showed that it was almost identical to $R$. japonica found in ticks \\ and Japanese spotted fever (JSF) patients previously reported. \\ Text-800 words
}


Ticks (Acari: Ixodidae) have been considered as important vectors of various infectious agents in Southeast Asia including spotted fever group (SFG) rickettsiae, and especially Rickettsia japonica causing Japanese spotted fever (JSF) which can be transmitted to humans through infected ticks (1). JSF has mainly been reported in Japan, South Korea, China, and the Philippines (1). In Thailand, human infection with Rickettsia sp. related to R. japonica was first reported in a male patient (2). Later, the strain TCM1 of Rickettsia sp. related to R. japonica was successfully isolated from a Haemaphysalis hystricis tick found on Mt. Doi Suthep, northern, Thailand, but the identity of its host was not reported (3). Although ticks are known as the potential vectors of SFG rickettsiae $(1,4)$, in Thailand, there is very little known about interaction between vectors and mammalian host reservoirs.

To investigate the association of mammalian hosts parasitized by ticks infected with SFG rickettsiae, we examined 8 nymphs of $H$. hystricis removed from a fresh roadkill Burmese ferretbadger (Melogale personata) in northeastern Thailand centration in October 2019. Each individual nymph was washed in $10 \%$ bleach, $70 \%$ ethanol, and sterile distilled water three times (5 min each). DNA was extracted from 2 pooled nymphs (4 nymphs/pool) using the QIAamp DNA Extraction Kit for Tissue (QIAGEN) according to the manufacturer's protocol. The presence of Rickettsia spp. was examined by Polymerase Chain Reaction (PCR). One pool of nymphs was PCR-positive and was subjected to DNA sequencing targeting the partial rickettsial 17-kDa antigen gene (5), the citrate synthase gene ( $g l t \mathrm{~A})$, outer membrane protein A (ompA) (6) and B (ompB) genes. In this study, a new set of primers was designed to amplify the rickettsial ompB region (800 bp product size); RicF: CAG CAA GGT AAT AAG TTT AAT AC and RicR: GCT ATA CCG CCT GTA GTA ACA G; Cycling conditions in PCR were $95^{\circ} \mathrm{C}$ for 5 min, 30 cycles of $95^{\circ} \mathrm{C}$ for $1 \mathrm{~min}, 56^{\circ} \mathrm{C}$ for $1 \mathrm{~min}, 72^{\circ} \mathrm{C}$ for $1 \mathrm{~min}$, and a final cycle of $72^{\circ} \mathrm{C}$ for $10 \mathrm{~min}$. 
The sequences for Rickettsia sp. in pooled nymphs of $H$. hystricis from Thailand (HHT) used in this study were submitted to the GenBank accession numbers MW415892 (17-kDa antigen), MW415894 (gltA), MW415896 (ompA), and MW415898 (ompB).

BLASTn analyses revealed that the rickettsial partial sequences of $17-\mathrm{kDa}$ antigen and gltA genes were identical to several strains of $R$. japonica, $R$. vini, and $R$. raoultii deposited in GenBank. Since these two genes are highly conserved they are consequently not appropriate to differentiate species and/or strains of Rickettsia in this study. In contrast, the ompA and omp B genes are more variable and they therefore were employed in this study. BLAST results revealed that the ompA sequence obtained from $H$. hystricis nymphs removed from the Burmese ferretbadger was nearly identical (99.57\%) to R. japonica infected humans in China (access. no. CP047359, KY347792-3), Japan (access. no. AP017581, LC101443, U43795), Korea (access. no. DQ019319), and the strain TCM1 isolated from H. hystricis in Thailand (access. no. AB359459). However, the sequence was quite distantly related to Rickettsia sp. infecting humans in Thailand (access. no. DQ909072) (Figure). The sequence of the $o m p B$ gene of the same sample was identical to $R$. japonica infecting humans in China (access. no. CP047359, CP032049) (7) and H. hystricis (access. no. AP017586 - 8, AP017579) in Japan (8). Unfortunately, sequences of available and could not be included in this study. Based on nucleotide BLAST results, the unknown Rickettsia sp. detected in the H. hystricis ectoparasites of Burmese ferret-badger is most likely $R$. japonica. This is also supported by phylogenetic analyses based on partial ompA and $\operatorname{omp} \mathrm{B}$ gene sequences using neighbor-joining, maximum parsimony, maximum likelihood and Bayesian methods. All phylogenetic methods revealed similar tree topologies thus only the neighbor-joining trees are shown (Figure). It is obvious that our Rickettsia sp. was clustered with 
$R$. japonica with strong support (>90\%). The results thus clearly demonstrated that the $H$. hystricis nymphs were infected with $R$. japonica. Therefore, the Burmese ferret-badger is a potential reservoir of $R$. japonica which could be transmitted to human via tick vectors such as H. hystricis in Thailand.

A variety of tick species are ectoparasites of a wide range of domestic and wild mammals (9). The wild fauna may serve as reservoirs of SFG rickettsiae and JSF that can be transmitted to humans through infected ticks (10). We have demonstrated for the first time an association of $H$. hystricis ticks infected with $R$. japonica and a wild mammalian host in Thailand. Further investigations on the abundance and distribution of $H$. hystricis ticks parasitizing wild mammals and the prevalence of rickettsial infection in the vectors and hosts are necessary for better understanding the epidemiology of SFG rickettsiae and other tick-borne diseases in Thailand and Southeast Asia.

\section{Acknowledgments}

We thank Dr. Adrian Plant for invaluable comments.

This research was partially supported by Mahidol University, the Thailand Research Fund-Chinese Academy of Science Grant (DBG6180027), and the Center of Excellence on Biodiversity, Office of Higher Education Commission (BDC-PG3-163005 and BDC-PG3161006).

\section{About the Author}

Dr. Hirunkanokpun is an assistant professor in the Department of Biology, Faculty of Science, Ramkhamhaeng University. Her research interests include ecology of vectors and hostvector-pathogen interactions. 


\section{References}

1. Low VL, Tan TK, Khoo JJ, Lim FS, AbuBakar S. An overview of rickettsiae in Southeast Asia: vector-animal-human interface. Acta Trop. 2020;202:105282. https://doi.org/10.1016/j.actatropica.2019.105282

2. Gaywee J, Sunyakumthorn P, Rodkvamtook W, Ruang-areerate T, Mason CJ, Sirisopana N. Human infection with Rickettsia sp. related to R. japonica, Thailand. Emerg Infect Dis. 2007;13:657-9. https://doi.org/10.3201/eid1304.060585

3. Takada N, Fujita H, Kawabata H, Ando S, Sakata A, Takano A, et al. Spotted fever group Rickettsia sp. closely related to R. japonica, Thailand. Emerg Infect Dis. 2009;15:610-1. https://doi.org/10.3201/eid1504.071271

4. Parola P, Paddock CD, Socolovschi C, Labruna MB, Mediannikov O, Kernif T, et al. Update on tick-borne rickettsioses around the world: a geographic approach. Clin Microbiol Rev. 2013;26:657-702. https://doi.org/10.1128/CMR.00032-13

5. Williams SG, Sacci JB Jr, Schriefer ME, Andersen EM, Fujioka KK, Sorvillo FJ, et al. Typhus and typhus like rickettsiae associated with opossums and their fleas in Los Angeles county, California. J Clin Microbiol. 1992;30:1758-62. https://doi.org/10.1128/JCM.30.7.1758-1762.1992

6. Regnery RL, Spruill CL, Plikaytis BD. Genotypic identification of rickettsiae and estimation of intraspecies sequence divergence for portions of two rickettsial genes. $\mathbf{J}$ Bacteriol. 1991;173:1576-89. https://doi.org/10.1128/jb.173.5.1576-1589.1991

7. Lu, Q., Yu, J., Yu, L., Zhang, Y., Chen, Y., Lin, M, et al. Rickettsia japonica infections in humans, Zhejiang Province, China, 2015. Emerg infect Dis. 2018;24: 2077-79. https://doi.org/10.3201/eid2411.170044 
8. Akter A., Ooka T., Gotoh Y., Yamamoto S., Fujita H., Terasoma F., et al. Extremely low genomic diversity of Rickettsia japonica distributed in Japan. Genome Biol Evol. 2017;9:124-133. https://doi.org/10.1093/gbe/evw304

9. Morand S, Chaisiri K, Kritiyakan A, Kumlert R. Disease ecology of rickettsial species: a data science approach. Trop Med Infect Dis. 2020;5:64.

https://doi.org/10.3390/tropicalmed5020064

10. Satjanadumrong J, Robinson MT, Hughes T, Blacksell SD. Distribution and ecological drivers of spotted fever group Rickettsia in Asia. Ecohealth. 2019;16:611-626. https://doi.org/10.1007/s10393-019-01409-3

Address for correspondence: Wachareeporn Trinachartvanit, 272 Department of Biology, Faculty of Science, Mahidol University, Rama 6 Road, Ratchathewi, Bangkok 10400, Thailand; email: wachareeporn.tri@mahidol.ac.th

Figure. Neighbor-joining trees of Rickettsia japonica in Haemaphysalis hystricis in Thailand (HHT: indicated in bold characters) based on partial sequences of the $\operatorname{ompA}(\mathrm{A})$, and $о m p \mathrm{~B}(\mathrm{~B})$ genes amplified from pooled nymphs of $H$. hystricis. Variability within some clades were collapsed into triangles for visualization. The bootstrap values for neighbor-joining, maximum parsimony, maximum likelihood and probability for Bayesian analysis were shown above branch. Scale bar indicates nucleotide substitutions per site. The name of each sequence containing the GenBank accession number is followed by the name of the Rickettsia species, host species and country of origin. 
bioRxiv preprint doi: https://doi.org/10.1101/2021.02.23.432398; this version posted February 23, 2021. The copyright holder for this preprint (which was not certified by peer review) is the author/funder. All rights reserved. No reuse allowed without permission.

A

ompA gene

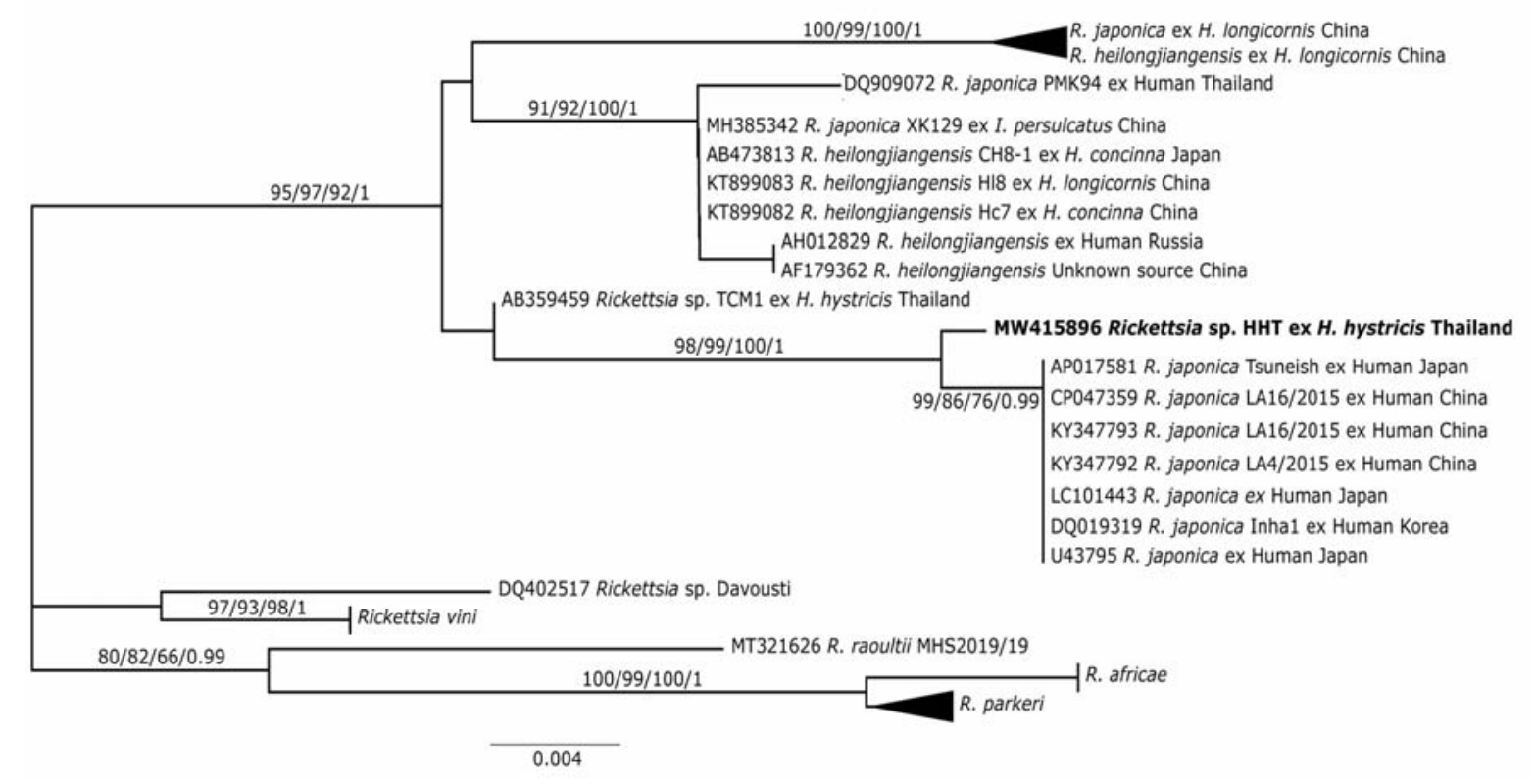

B

\section{ompB gene}

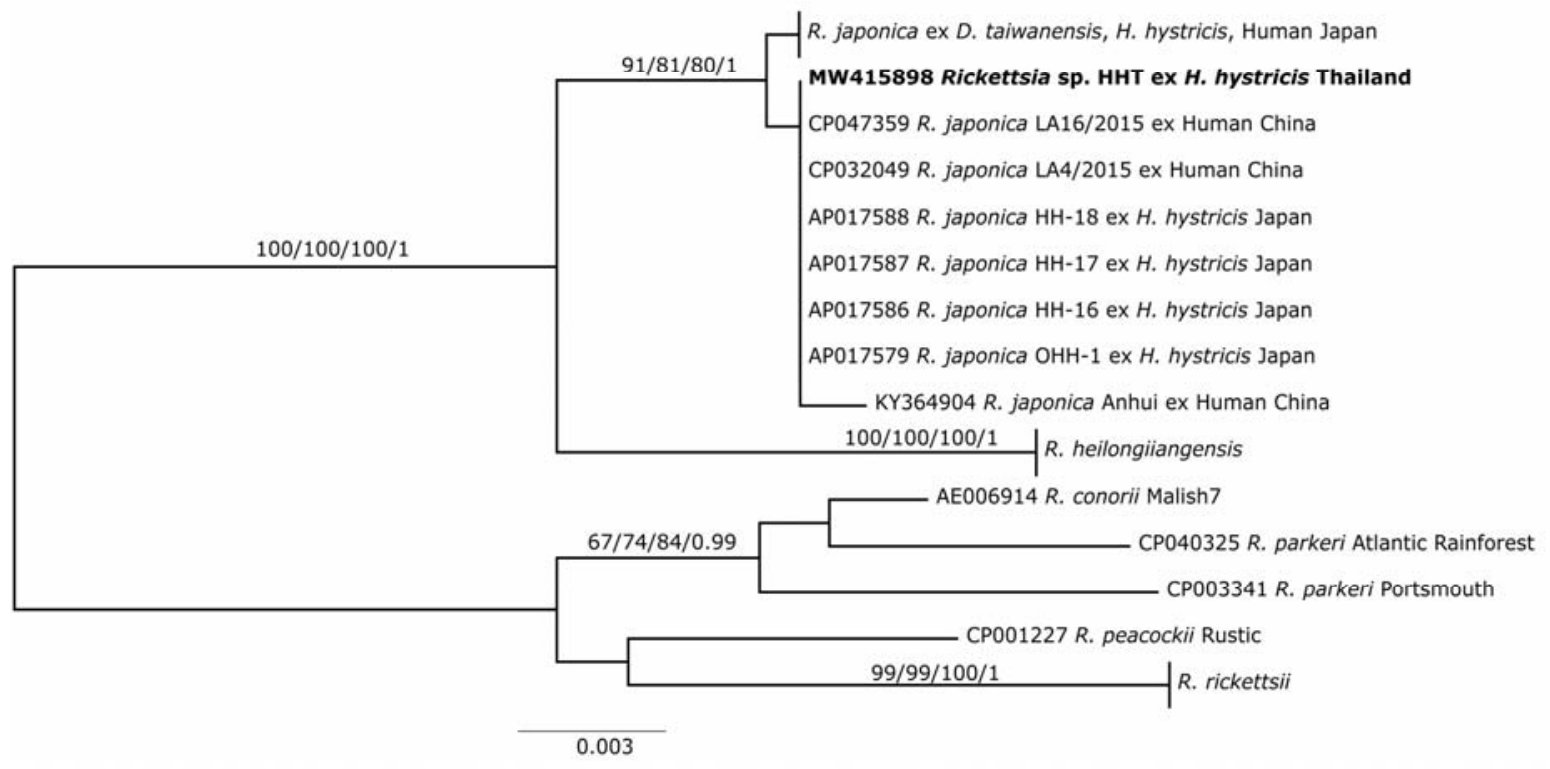

